\title{
AS PROVAS DA EXISTÊNCIA DE DEUS EM DESCARTES
}

Luciano Marques de Jesus*

STNTESE - $O$ artigo tematiza as chamadas provas da existência de Deus na filosofia de René Descartes. A primeira, propriamente cartesiana, parte da idéia de infinito, presente no eu, para a existência do Ser infinito; a segunda, versão cartesiana do argumento da contingentia mundi, parte da existência do eu contingente que possui a idéia para a existência de Deus; a terceira é uma reedição do argumento ontológico de Santo Anselmo.
ABSTRACT - The article is about the so-called proofs of God's existence in René Descartes' philosophy. The first one, Cartesian itself, comes from the idea of infinite present in the self for the existence of the infinite being; the second one, Cartesian version of the argument of contingentia mundi, is originated from the existence of the contingent self that has the idea to God's existence; the third one is a re-edition of Saint Anselm's ontologic argument.

Descartes apresenta três argumentos para provar a existência de Deus: nos dois primeiros procede a partir dos efeitos (da idéia de Deus presente no sujeito e do sujeito que possui a idéia de Deus), causalmente; no terceiro, em que procede a priori, chamado desde Kant de argumento ontológico, ${ }^{1}$ deduz da idéia de Deus a sua existência. A questão de Deus é exposta em vários escritos: na quarta parte do Discurso do método (DM); na terceira (os dois primeiros argumentos) e na quinta (o terceiro argumento) das Meditações metafisicas (M) (na quarta, cujo título é Do verdadeiro e do falso, Deus aparece como garantia do conhecimento verdadeiro); na primeira parte dos Princípios da Filosofia (PF) e nas Respostas às objeções (especialmente nas primeiras e segundas).

Cumpre apontar as diferenças entre as diversas exposições. ${ }^{2}$ No Discurso e nas Meditações, Descartes segue aquilo que chama de "ordem de descoberta", ${ }^{3}$

* Professor do Instituto de Filosofia e Ciências Humanas da PuCRS.

1 KANT, Immanuel. Critica da razão pura. Lisboa: Fundação Calouste Gulbenkian, 1985, p. 500 (L. I, $2^{\mathrm{a}} \mathrm{p}, 2^{\mathrm{a}} \mathrm{d}, \mathrm{L} 2$, cap. $3,4^{\mathrm{a}}$ secção).

2 Entre as Meditações e o Discurso, cabe ressaltar uma diferença fundamental, que acusa, outrossim, a diversidade de perspectiva. A noção de veracidade divina só aparece nas Meditaçōes, no Discurso não aparece, como Descartes não levantou ai a idéia de um Deus enganador, não precisa refutá-la. Mas Deus é, no Discurso, o fundamento da verdade das idéias claras e distintas.

3 "[...] l'ordre ne sont pas les mêmes, pour l'invention et pour l'exposition" (Entretien avec Burman, OL, p. 1364).

\begin{tabular}{|l|l|l|l|l|l|} 
VERITAS & Porto Alegre & v. 43 & $\mathrm{n}^{2} 2$ & Junho 1998 & p. $347-364$ \\
\hline
\end{tabular}


ao passo que nos Princípios segue a "ordem de exposição", invertendo a ordem de descoberta e apresentando o argumento ontológico em primeiro lugar. ${ }^{4}$ Jesús García López afirma que no Discurso as provas estão expostas em forma genética, nas Meditações, em forma sistemática e muito mais extensa, e nos Principios e nas Respostas, em forma sintética. ${ }^{5}$

As provas cartesianas da existência de Deus não partem, como as vias tradicionais, das criaturas, do mundo e do movimento para a causa primeira. As provas cosmológica e teológica pressupõem a existência do mundo, que neste lugar do itinerário cartesiano é ainda duvidosa. O ponto de partida das provas cartesianas serão as conclusões do cogito: a existência dos meus pensamentos e do eu que os possui. No dizer de U. Zilles, "o caminho cartesiano vai do cogito a Deus, a verdade objetiva". ${ }^{6} \mathrm{Ou}$, ainda, na expressão de Edmundo Luís Kunz:

"Enveredando por outros caminhos, que não o dos pensadores da escolástica, Descartes deu início à via que conduz o espirito humano a Deus, a partir de si mesmo."7

\section{A primeira prova}

Realizado o inventário das idéias que jaziam no cogito, resta a Descartes somente a idéia de Deus, na qual é preciso considerar se há algo que não tenha vindo do próprio sujeito. Sobre a idéia que tem de Deus, escreve Descartes, na Meditação Terceira:

"Pelo nome de Deus entendo uma substância infinita, eterna, imutável, independente, onisciente, onipotente e pela qual eu próprio e todas as coisas que são (se é verdade que há coisas que existem) foram criadas e produzidas"8 (M, II, 22, p. 39).

Quanto mais Descartes considera estas "vantagens" da idéia de Deus, mais fica persuadido de que o eu não pode tirar esta idéia de si tão-somente. Logo, deve-se concluir que Deus existe.

De onde provém a idéia de Deus (substância infinita) que está presente no eu? Ainda que o eu possua a idéia de substância, pelo próprio fato de ser uma substância (res cogitans), não teria a idéia de uma substância infinita, ele que é um ser finito (que duvida, e existe maior perfeição em conhecer do que em duvidar), se esta não tivesse sido nele colocada por uma substância realmente infinita. A realidade objetiva da idéia de Deus exige como realidade formal que a causou, a existência de Deus.

4 Fraile inicia a exposição das provas cartesianas como os Principios, pelo argumento a priori. Considera a ordem dos Principios e das Respostas às Segundas objeções como "más técnica e rigurosa" (FRAIIE, Guillermo. Historia de la Filosofia. Madrid: BAC, 1996. vol. II, p. 525).

5 "En el Discurso del Método está expuesta en forma que podemos llamar genética; en las Meditaciones adquire ya una formulación sistemática y mucho más extensa, y en los Principios de la Filosofia y en las Respuestas a las Segundas objeciones tiene forma sintética (LÓPEZ, Jesús García. El conocimiento de Dios en Descartes. Pamplona: Ediciones Universidad de Navarra, 1976, p. 65). ZLLLES, Urbano. Filosofia da Religiāo. São Paulo: Paulinas, 1991, p. 29.

7 KUNZ, Edmundo Luis. Deus no espaço existencial. Porto Alegre: EST/Sulina, 1975, p. 28.

8 "Par le nom de Dieu j'entends une substance infinie, éternelle, immuable, indépendante, toute connaissante, toute puissante, et par laquelle moi-même, et toutes les autres choses qui sont ( $\mathrm{s}$ 'il est vrai qu'il y en ait qui existent) ont été créées et produites" (OL, p. 294; AT IX-1, p. 35-36). 
A idéia do infinito não pode ser obtida pela negação do finito, pois há mais realidade na substância infinita que numa substância finita. $\mathrm{O}$ eu possui a noção do infinito antes da noção do finito, isto é, afirma Descartes, "de Deus antes de mim mesmo"9 (M, III, 23, p. 40). Esta noção de anterioridade do infinito parece contradizer a perspectiva de Alquié, de que é no caráter pessoal e finito do eu que vai assentar a dialética que nos levará até Deus. É preciso esclarecer que no processo psicológico da argumentação, o ponto de arranque é a dúvida, ou melhor, o conhecimento da própria dúvida ou da própria imperfeição, finitude (No Discurso, IV, p. 47, afirma Descartes, "tendo refletido sobre aquilo que duvidava, e que, por conseqüência, meu ser não era inteiramente perfeito [...]"10) $O$ ponto de partida do processo lógico de demonstração da primeira prova cartesiana da existência de Deus, ${ }^{11}$ porém, é a idéia de Deus (infinito). Para Geneviève Rodis-Lewis:

"A originalidade de Descartes consiste em fazer do infinito positivo a própria condição do pensamento do negativo [...]. O infinito é ontologicamente primeiro em relação ao finito, mesmo se cronologicamente a primeira certeza é a do meu ser finito. A este respeito é essencial que o Cogito não tenha atingido de imediato o Pensamento universal e intemporal."12

Rodis-Lewis afirma, ainda, que a argumentação de Descartes conclui da finitude do eu a impossibilidade do eu ser a causa deste infinito positivo representado pela idéia que o eu possui deste. E continua:

"Assim se instaura uma verdadeira dialética ascendente, em que o ser limitado do ego pensante se subordina ao Ser infinito, único capaz de ser absolutamente Princípio". ${ }^{13}$

Como a idéia de Deus é muito clara e distinta e contém mais realidade objetiva do que qualquer outra, apresenta-se como a idéia mais verdadeira e menos sujeita a erro e falsidade. Tudo o que é concebido clara e distintamente de real e verdadeiro pelo meu espírito, e que contém em si alguma perfeição, está contido na idéia de Deus.

Isto é verdadeiro, mesmo que não se compreenda o infinito. Não obstante a sua incompreensibilidade, Deus pode ser conhecido. Descartes recebeu de seus contemporâneos a objeção de como é possivel conhecer clara e distintamente um ser incompreensivel. Mantém sempre que:

"Basta [...] que julgue que todas as coisas que concebo claramente, e nas quais sei que há
alguma perfeição, e talvez também uma infinidade de outras que ignoro, estão em Deus
formal ou eminentemente, para que a idéia que dele tenho seja a mais verdadeira, a mais
clara e a mais distinta dentre todas as que se acham em meu espirito"14 (M, II, 27, p. 40).

9 “[...] c'est-à-dire de Dieu, que de moi-même" (OL, p. 294; AT IX-1, p. 36).

10 "[.... faisant réflexion sur ce que je doutais, et que, pour conséquent, mon être n'était pas tout parfait” (OL, p. 148; AT VI, p. 33).

11 Cf. LÓPEZ, J.G. El conocimiento de Dios en Descartes, p. 67.

12 RODIS-LEWIS, Geneviève. Descartes e o racionalismo. Porto: Rés, 1979, p. 42.

13 Idem.

14 " [...] et il suffit que je conçoive bien cela, et que je juge que toutes les choses que je conçois clairement, et dans lesquelles je sais qu'il y a quelque perfection, et peut-être aussi une infinité d'autres que j'ignore, sont en Dieu formellement ou éminemment, afin que l'idée que j'en ai soit la plus vraie, la plus claire et la plus distincte de toutes celles qui sont en mon esprit" (OL, p. 295; AT IX-1, p. 37). 
Há a possibilidade de que as perfeições atribuídas a um Deus pertençam ao eu potencialmente. Descartes verifica que o conhecimento do eu aumenta e se aperfeiçoa pouco a pouco e nada impede que aumente até o infinito. Isto, porém, não se aproxima da idéia que o eu tem de Deus, pois Nele nada se encontra de potência, mas somente em ato e efetivamente. Ademais, o fato de aumentar gradativamente, manifesta aperfeiçoamento do eu e, portanto, imperfeição. Ao mesmo tempo, Deus é concebido como atualmente infinito, que nada se pode acrescentar à sua perfeição. E o ser objetivo de uma idéia não pode ser produzido por um ser que exista só potencialmente.

Nos Princípios este argumento aparece, como já foi referido, após o argumento a priori, e sua exposição constitui-se num excelente epítome de toda a argumentação:

“[...] por encontrarmos em nós a idéia de um Deus ou de um Ser sumamente perfeito, podemos investigar a causa que determina que esta idéia seja em nós. Todavia, depois de ter ponderado, com a devida atenção, quão imensas são as perfeições que tal idéia nos representa, somos constrangidos a confessar que só a poderiamos ter a partir de um ser muito perfeito" ${ }^{15}$ (PF, I, 18, p. 67).

\section{Prossegue com o princípio de causalidade:}

"Ou seja: de um Deus que é verdadeiramente ou que existe, por isso que, não somente é manifesto, pela luz natural, que o nada não pode estar à volta do que quer que seja, e que o mais perfeito não poderia ser uma continuação ou uma dependência do menos perfeito, mas também por verificarmos, por meio desta mesma luz, que é impossivel que tenhamos a idéia ou a imagem do que quer que seja, se não há, em nós ou fora de nós, um original que compreende, com efeito, todas as perfeições que assim se nos representam"16 (PF, I, 18, p. 67-68).

\section{Conclui:}

"Mas como bem sabemos que estamos submetidos a muitas imperfeições, e que não possuímos essa extrema perfeição de que temos a idéia, cumpre-nos concluir que elas estão em alguma natureza diferente da nossa e, na verdade, muito perfeita, isto é, Deus"17 (PF. I, 18, p. 68).

No Discurso, o eu reflete sobre sua dúvida, constata que não é perfeito, pois percebe ćlaramente que há mais perfeição em conhecer do que em duvidar. Procura saber, então, de onde aprendeu a pensar em algo mais perfeito do que si

15 “...] parce que nous trouvons en nous l'idée d'un Dieu, ou d'un être tout parfait, nous pouvons rechercher la cause qui fait que cette idée est en nous; mais, après avoir considéré avec attention combien sont immenses les perfections qu'elle nous représente, nous sommes contraints d'avouer que nous ne saurions la tenir que d'un être très parfait" (OL, p. 579; AT IX-2, p. 33).

16 “[...] c'est-à-dire d'un Dieu qui est véritablement ou qui existe, parce qu'il est non seulement manifeste par la lumière naturelle que le néant ne peut être auteur de quoi que ce soit, et que le plus parfait ne saurait être une suite et une dépendance, du moins parfait, mais aussi parce que nous voyons par le moyen de cette même lumière qu'il est impossible que nous ayons l'idée ou l'image de quoi que ce soit, s'il n'y a en nous ou ailleurs un original qui comprenne en effet toutes les perfections qui nous sont ainsi représentées" (OL, p. 579; AT IX-2, p. 33).

17 "[...] Mais comme nous savons que nous sommes sujets à beaucoup de défauts, et que nous ne possédons pas ces extrêmes perfections dont nous avons l'idée, nous devons conclure qu'elles sont en quelque nature qui est diffėrente de la nôtre, et en effet très parfaite, c'est-à-dire qui est Dieu" (OL, p. 579; AT IX-2, p. 33). 
próprio, algo que deveria ser de natureza mais perfeita. Percebe que uma tal idéia não provém nem das coisas exteriores (como céu, terra, luz, etc.), nem de si mesmo. E aplicando o princípio de causalidade afirma:

\begin{abstract}
"De forma que restava apenas que tivesse sido posta em mim por uma natureza que fosse verdadeiramente mais perfeita do que a minha, e que mesmo tivesse em si todas as perfeições de que poderia ter alguma idéia, isto é, para explicar-me numa palavra, que fosse Deus"18 (DM, IV, p. 47).
\end{abstract}

Para Jacques Maritain, a primeira prova cartesiana da existência de Deus não obteve, diferentemente do argumento ontológico, êxito histórico. ${ }^{19}$ Mas foi a esta prova que Descartes atribuiu uma importância maior; no Resumo das Meditações, afirma que é "o principal argumento de que me sirvo para provar a existência de

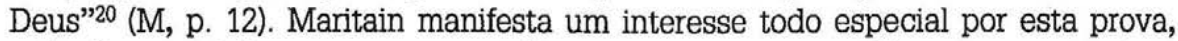
pois ela possui "uma certa concepção estritamente e especificamente cartesiana das idéias". ${ }^{21}$ Esta é a prova mais propriamente cartesiana, conquanto, como se verá mais adiante, a segunda é chamada de versão cartesiana do argumento da contingentia mundi e a terceira, a versão cartesiana do argumento ontológico.

Após reproduzir a argumentação cartesiana da primeira prova da existência de Deus, Jesús García López constata que esta não possui a mesma força e rigor em todas as suas partes. ${ }^{22}$ Além de uma formulação não-evidente do princípio de causalidade eficiente, López aponta mais duas debilidades na argumentação. A primeira é quando Descartes afirma que nosso pensamento, nosso eu, não pode produzir a realidade objetiva da idéia de Deus, já que é mais imperfeito. Ora, para afirmar esta impossibilidade, é necessário demonstrar primeiro que nosso eu é efetivamente imperfeito e que nada há em nós que não conheçamos, ou seja, que o conhecimento que temos do eu esgota, até o último resíduo, a inteligibilidade dele mesmo. A segunda insuficiência reside na afirmação de que é impossivel uma série infinita de idéias causadas e que há que se chegar numa primeira causa, que não seja uma idéia, mas um ser real. Para López, como se verá adiante na segunda prova, estas insuficiências são sanadas por uma fundamentação mais firme. 0 primeiro aspecto será solucionado, quando Descartes reduzir o eu ao puro pensamento e o segundo aspecto, quando distinguir entre a causa que os produziu no passado e a que nos conserva no presente. Porém, ficando-se restrito à primeira prova, as deficiências mencionadas permanecem sem uma fundamentação adequada.

Um dos aspectos mais criticados deste argumento cartesiano é o principio de causalidade. George Pascal observa que não deixaram de fazer a Descartes a objeção de que seu axioma era desmentido pela experiência e que, afirma,

18 “De façon qu'il restait qu'elle eût été mise en moi par une nature qui fût véritablement plus parfaite que je n'étais, et même qui eût en soi toutes les perfections dont je pouvais avoir quelque idée, c'est-à-dire, pour m'expliquer en un mot, qui fût Dieu" (OL, p. 149; AT VI, p. 34). MARITAIN, Jacques. Le songe de Descartes. Paris: Buchet/Chastel. ca. 1931, p. 154.

20 "[...] le principal argument dont je me sers pour prouver l'existence de Dieu" (Abrégé des six méditations suivantes, OL, p. 264; AT IX-1, p. 11).

21 "[...] une certaine conception strictement et spécifiquement cartésienne des idées" (MARITAIN, J. Le songe de Descartes, p. 154).

22 LÓPEZ, J. G. El conocimiento de Dios en Descartes, p. 77. 
"[...] se via bem que alguns efeitos podiam ser, de certa maneira, superiores às suas causas: o Sol, a chuva, a terra, que não têm vida, produzem plantas e animais, seres vivos, o que mostra que pode haver um grau a mais de perfeição no efeito do que na causa."23

A isto Descartes contrapõe que não conhecemos todas as causas da geração das plantas e dos animais e, então, não é razoável pensar que o Sol, a chuva e a terra sejam a causa "total" desta geração. George Pascal assinala, ainda, a resposta de Descartes à objeção de Gassendi:

"Da mesma forma, a Gassendi, que lhe objetou que seu axioma deve ser entendido mais como atinente à causa material [...], Descartes responde que a perfeição da forma não pode provir da causa material, mas somente da causa eficiente."24

Também John Cottingham afirma que o ponto que mais suscitou a critica dos contemporâneos de Descartes foi a aplicação do principio da causalidade no reino das idéias. ${ }^{25}$ Para os objetores, uma idéia não passa de uma realidade subjetiva, não é uma entidade real. Apresenta Cottingham a réplica de Descartes:

"Descartes respondeu que, embora as idéias não tenham existência fora da mente, isso não irá de forma alguma eliminar a necessidade de uma explicação causal de uma idéia que tenha um determinado conteúdo."26

E acrescenta:

"Nisto, ele [Descartes] parece estar perfeitamente correto e, com efeito, o Princípio de Adequação Causal parece realmente assentar em terreno mais firme, quando é aplicado às idéias do que quando é aplicado ao mundo fisico."27

Este primeiro argumento cartesiano é chamado, por Cottingham, de "argumento da marca impressa"28 (embora Descartes use esta expressão somente no final da Meditação Terceira, após a apresentação do segundo argumento). Esta alcunha deve-se ao fato de Descartes invocar a idéia de Deus ter colocado no eu a idéia de si mesmo: "E certamente não se deve achar estranho que Deus, ao me criar, haja posto em mim esta idéia para ser como a marca do operário impressa em sua obra"29 (M, III, 39, p. 44).

Ainda com respeito ao primeiro argumento, Cottingham afirma que Descartes segue uma linha de raciocínio bastante convencional, que pode ser remontada a São Boaventura, Santo Agostinho e Platão: ${ }^{30}$

“[...] pode ser encontrada, por exemplo, no Itinerarium mentis in Deum, de São Boaventura (1259): 'Como poderia o intelecto reconhecer-se um ser defeituoso e incompleto senão tendo algum conhecimento de um ser livre de todos os defeitos?' (cap. III, seção 4). Trata-se, essencialmente, de uma variação de um argumento anterior, de Santo Agostinho (extraido em última análise de Platão): a capacidade de fazer juizos comparativos ( $x$ é melhor do que

23 PASCAL, George. Descartes. São Paulo: Martins Fontes, 1990, p. 62.

24 Id., ibidem, p. 63.

25 COTTINGHAM, John. A Filosofia de Descartes. Lisboa: Edições 70, 1989, p. 78.

26 Idem.

27 Idem.

28 Id., ibidem, p. 73 ,

29 "Et certes on ne doit pas trouver étrange que Dieu, en me créant, ait mis en moi cette idée pour être comme la marque de l'ouvrier empreinte sur son ouvrage" (OL, p. 299; AT IX-1, p. 41).

30 PLATÃO. F'édon. São Paulo: Abril Cultural (Coleção Os Pensadores, n. 3), 1972, p. 83, 74a s. 
y) não poderia existir a não ser que tivéssemos em nós uma noção de bem perfeito, ou Deus (cf. Santo Agostinho, De Trinitate, L. VIII, cap. 3, seção 4)."31

Cottingham aponta, noutro lugar, um paradoxo da metafísica de Descartes: ao mesmo tempo em que pretende eliminar as opiniões preconcebidas e começar tudo $a b$ ovo, ${ }^{32}$ desde os fundamentos,

"[...] a base de seu pensamento deve muito a uma cuidadosa fusão entre a metafisica platônica e a cristã; sem esse aparato, a transição crucial do autoconhecimento para o conhecimento de Deus e a subseqüente validação da ciência não podem ser alcançadas"33.

\section{A segunda prova}

Na segunda prova cartesiana, Deus não é considerado somente como o autor de sua idéia que está presente no eu, mas como o criador do próprio eu. No Discurso, Descartes escreve:

"[...] dado que conhecia algumas perfeições que não possuía, eu não era o único ser que existia (usarei aqui livremente, se vos aprouver, alguns termos da Escola); mas que devia necessariamente haver algum outro mais perfeito, do qual eu dependesse e de quem eu tivesse recebido tudo o que possuia"34 (DM, IV, p. 48).

\section{Ora, nos Principios, Descartes afirma que é evidente}

"[...] que aquele que conhece alguma coisa de mais perfeito do que ele próprio, não deu a si próprio o ser, visto que, pela mesma mediação, ter-se-ia dado todas as perfeições de que tivesse conhecimento" ${ }^{35}$ (PF, I, 20, p. 69).

Não é o eu, portanto, a causa de si próprio, pois é imperfeito, e subsiste por meio daquele que possui todas as perfeições: Deus.

Nas Meditações, Descartes se pergunta se poderia existir (note-se: o eu tem a idéia de Deus), no caso de Deus não existir. E segue interrogando, de onde o eu tiraria a existência. De si mesmo, dos pais, ou de qualquer outra causa menos perfeita que Deus, visto que nada se pode imaginar de mais perfeito ou de igual a Deus. Ora, afirma Descartes,

“[...] se eu fosse independente de todo outro ser, e fosse eu próprio o autor de meu ser, certamente não duvidaria de coisa alguma, não mais conceberia desejos e, enfim, não me faltaria perfeição alguma; pois eu me teria dado todas aquelas de que tenho alguma idéia e assim seria Deus"36 (M, III, 31, p. 41).

31 COTTINGHAM, J. Dicionário Descartes. Rio de Janeiro: Jorge Zahar Editor, 1995, verbete "marca impressa argumento da", p. 105.

32 ZILLES, U. Filosofia da Religião, p. 25.

33 COTTINGHAM, J. Dicionário Descartes, verbete "causa", p. 30.

34 “[...] que, puisque je connaissais quelques perfections que je n'avais point, je n'étais pas le seul être qui existât (j'userai, s'il vous plait, ici librement des mots de l'École); mais qu'il fallait de nécessité qu'il y en eût quelque autre plus parfait, duquel je dépendisse, et duquel j'eusse acquis tout ce que j'avais" (OL, p. 149; AT VI, p. 34).

35 "[...] que ce qui connait quelque chose de plus parfait que soi ne s'est point donné l'être, à cause que par même moyen il se serait donné toutes les perfections dont il aurait eu connaissance" (OL, p. 580; AT IX-2, p. 34).

36 “[...]si j'étais indépendant de tout autre, et que je fusse moi-même l'auteur de mon être, certes je ne douterais d'aucune chose, je ne concevrais plus de désirs, et enfin il ne me manquerait aucune perfection; car je me serais donné moi-même toutes celles dont j'ai en moi quelques idées, et ainsi je serais Dieu" (OL, p. 296; AT IX-1, p. 38). 
Descartes apresenta aqui a hipótese de o eu existir sem causa, hipótese que fica invalidada pela descontinuidade e independência dos momentos do tempo e, conseqüentemente, pela necessidade de o eu ser conservado, a cada instante, por uma causa. Sobre isto, escreve Alquié:

"A doutrina da criação contínua permite retomar de novo, com mais força um tal raciocínio ('aquilo que conhece alguma coisa mais perfeita que si próprio não se deu o ser'). O tempo, feito de instantes, é descontínuo. A análise do cogito revela-me que a minha existência se limita ao momento presente, sem garantia quanto ao futuro. Se, pois, o meu ser se conserva, é porque ele é continuamente criado por Deus." ${ }^{37}$

George Pascal, da mesma maneira, assinala o fortalecimento deste segundo argumento pela teoria da criação contínua:

"Esta prova da existência de Deus [...] acha-se fortalecida de certo modo pela teoria cartesiana, tirada dos escolásticos, da criação contínua. De fato, é um tema constante em Descartes que, como cada instante da duração é independente do instante anterior, 'a causa que é necessária para conservar uma coisa nāo é menor do que a que a produziu pela primeira vez'."38

Na seqüência da Meditação Terceira, Descartes retoma a possibilidade de o eu ter sido produzido pelos pais ou outras causas menos perfeitas que Deus. Recorre novamente ao princípio de causalidade, considerando como evidente que deve haver ao menos tanta realidade na causa quanto em seu efeito.

"E, portanto, já que sou uma coisa pensante, e tenho em mim alguma idéia de Deus, qualquer que seja, enfim, a causa que se atribua à minha natureza, cumpre necessariamente confessar que ela deve ser de igual modo uma coisa pensante e possuir em si a idéia de todas as perfeições que atribuo à natureza Divina" ${ }^{39}$ (M, II, 35, p. 43).

Descartes analisa, ainda, a possibilidade de que muitas causas tenham concorrido para a produção do eu e que a idéia de perfeição, atribuída a Deus, seja oriunda de várias causas ou se encontre algures no Universo e não em Deus. A isto, Descartes interpõe que uma das principais perfeições de Deus é a unidade, a simplicidade ou a inseparabilidade de todas as coisas que nele existem.

Encaminhando o final da Meditação Terceira, Descartes apresenta a idéia da marca do operário impressa na sua obra e acrescenta:

“[...] e não é tampouco necessário que essa marca seja algo diferente da própria obra. Mas pelo simples fato de Deus me ter criado, é bastante crivel que ele, de algum modo, me tenha produzido à sua imagem e semelhança e que eu conceba essa semelhança (na qual a idéia de Deus se acha contida) por meio da mesma faculdade pela qual me concebo a mim próprio" 40 (M, III, 39, p. 44).

37 ALQUTÉ, F. Galileu, Descartes e o mecanismo. 2. ed. Lisboa: Gradiva, 1987, p. 40-41.

38 PASCAL, George. Descartes, p. 66.

39 "Et partant, puisque je suis une chose qui pense, et qui ai en moi quelque idée de Dieu, quelle que soit enfin la cause que l'on attribue à ma nature, il faut nécessairement avouer qu'elle doit pareillement être une chose qui pense, et posséder en soi l'idée de toutes les perfections que j'attribue à la nature Divine" (OL, p. 298; AT IX-1, p. 39).

40 "Et il n'est pas aussi nécessaire que cette marque soit quelque chose de différent de ce même ouvrage. Mais de cela seul que Dieu m'a créé, il est fort croyable qu'il m'a en quelque façon produit à son image et semblance, et que je conçois cette ressemblance (dans laquelle l' idée de Dieu se trouve contenue) par la même facultè par laquelle je me conçois moi-même" (OL, p. 299-300; AT IX-1, p. 41). 
Isto equivale a dizer que mais do que o fato de a idéia de Deus estar presente no eu, o eu é a idéia de Deus. Escreve Alquié:

\begin{abstract}
"Portanto, porque o homem é a idéia de Deus é que Descartes, em 1630, pôde enunciar a teoria da criação das verdades eternas, isto é, superar, em direção ao infinito, toda a finitude, e aperceber como contingentes as próprias verdades que formam a necessária estrutura da sua razão. Porque o homem é a idéia de Deus é que Descartes pôde, pela dúvida, ultrapassar e negar o mundo das coisas, e depois, tomando reflexivamente consciência dessa mesma ultrapassagem, afirmar o cogito. E porque o homem é a idéia de Deus é que Descartes pode presentemente fundamentar o seu conhecimento: a consciência da minha finitude e a de Deus são uma e mesma consciência, da qual Deus e o eu são os dois pólos sucessivamente afirmados." 41
\end{abstract}

Alquié constata ainda que o homem não é um ser finito ordinário, mas um ser que tem consciência de sua finitude e por isso "é, na terra, o sinal de Deus". ${ }^{42} \mathrm{E}$ prossegue:

"A sua consciência permite-lhe encontrar o ser como condição de todo o pensamento e, portanto, depois de ter ligado por um instante o seu conhecimento ao ser do seu eu, que é um meio entre o ser e o nada, ligá-lo a Deus, que é o único verdadeiramente Ser."43

Desta maneira está fundamentada a verdade das idéias, como Descartes escreve a Cleselier: "[...] a idéia do infinito, compreendendo todo ser, compreende tudo o que há de verdadeiro nas coisas". ${ }^{4}$

Voltando à Meditação. Quando o eu reflete sobre si, não só se reconhece imperfeito e dependente, que aspira a algo melhor, mas descobre o próprio Deus. E toda a força do argumento apresentado, afirma Descartes,

“[...] consiste em que reconheço que seria impossivel que minha natureza fosse tal como é, ou seja, que eu tivesse em mim a idéia de um Deus, se Deus não existisse verdadeiramente" 45 (M, III, 39, p. 44).

Disso, infere-se que Deus não é embusteiro, pois o embuste é uma imperfeição, pois depende de alguma carência. $\mathrm{E}$ antes de examinar este aspecto de que Deus não é enganador, mas verídico e garantia do conhecimento, Descartes escreve este trecho, que não deixa de ser surpreendente:

“[...] parece-me muito a propósito deter-me algum tempo na contemplação deste Deus todo perfeito, ponderar totalmente à vontade seus maravilhosos atributos, considerar, admirar e adorar a incomparável beleza dessa imensa luz, ao menos na medida em que a força de meu espirito, que queda de algum modo ofuscado por ele, mo puder permitir"46 $(\mathrm{M}, \mathrm{II}, 41$, p. 44).

41 ALQUIÉ, F. A Filosofia de Descartes. 2. ed. Lisboa: Editorial Presença, 1986, p. 88.

42 Idem.

43 Idem.

44 Citado por AL.UUÉ, F. A Filosofia de Descartes, p. 88.

45 “[...] consiste en ce que je reconnais qu'il ne serait pas possible que ma nature fût telle qu'elle est, c'est-à-dire que j'eusse en moi l'idée d'un Dieu, si Dieu n'existait véritablement" (OL, p. 300; AT IX-1, p. 41).

46 “[...] il me semble très à propos de m'arrêter quelque temps à la contemplation de ce Dieu tout parfait, de peser tout à loisir ses merveilleux attributs, de considérer, d'admirer et d'adorer l'incomparable beauté de cette immense lumière, au moins autant que la force de mon esprit, qui en demeure en quelque sorte ébloui, me le pourra permettre" (OL, p. 300; AT IX-1, p. 41). 
Alguns comentadores consideram esta segunda prova como uma variação da primeira, ${ }^{47}$ outros a consideram como uma prova nova e logicamente distinta. ${ }^{48}$ Isto não importa muito para Descartes. ${ }^{49}$

Geneviève Rodis-Lewis afirma que a segunda prova executa o mesmo percurso da primeira, parte, não da idéia, mas da existência do eu. Porém, "o cerne do argumento continua ser a inerência em mim finito da idéia de infinito". 50 Qual é o fundamento de um ser contingente e finito? Proceder causalmente de forma indefinida atrás desta resposta não resolve o problema, somente $\circ$ faz recuar. Se o eu tivesse o poder de prolongar sua existência o faria sempre, porém não é assim que acontece, disso não tem consciência. Além disso, se o eu tivesse adquirido de si mesmo o pouco que possui, por que não teria dado a si mesmo a perfeição de que tem idéia? Prossegue Rodis-Lewis:

"Como na primeira prova, é o fosso impossivel de preencher entre a infinitude positiva e a minha negatividade que obriga a transpor os limites do Cogito, para aceder a um outro Ser, de que me descubro dependente. ${ }^{n 1}$

A segunda prova representa, para vários autores, a versão cartesiana do argumento chamado cosmológico. No ponto em que se encontra nas Meditações, Descartes nem sabe se o mundo existe, não pode, pois, fazer da contingentia mundi um argumento. Mas há uma existência de que o eu está certo, a sua própria. E dela partirá. A este respeito, afirma Jacques Maritain:

"Partir, para remontar até a causa primeira, da minha própria existência, de mim, sujeito pensante, antes que de uma outra existência, é uma simples variação sobre o tema da segunda via de Santo Tomás, na qual toda existência contingente indiferentemente é apta, desde o instante que ela é bem verificada, a servir de ponto de partida. Mas Descartes não procura a causa primeira de seu ser, ele busca a causa de seu ser enquanto pensa a idéia de Deus. As outras diferenças que ele assinala entre sua prova e a via tomista são ilusórias ou secundárias, aquela é essencial e fundamental; a prova cartesiana é original, ela procederá diferentemente das provas tradicionais." 52

Parece, efetivamente, que Descartes tenha intencionado com esta prova tornar o seu caminho mais compreensivel e aceitável aos tomistas, uma vez que para um tomista é inaceitável a possibilidade de "elevar-nos até Deus a título de uma

47 Neste grupo pode-se incluir George Pascal, John Cottingham, Jacques Maritain e Octave Hamelin.

48 Jesús Garcia López e Martial Guéroult, por exemplo.

49 Descartes escreve a Mesland, em 2 de maio de 1644: "Il importe peu que ma seconde démonstration, fondée sur notre propre existence, soit considérée comme différente de la première, ou seulement comme une explication de cette première" (OL, p. 1163). Geneviève Rodis-Lewis afirma que "pouco importa distinguir duas provas na $\mathrm{II}^{a}$ Meditação, ou ver na segunda uma explicação da primeira" (RODIS-LEWIS, G. Descartes e o racionalismo, p. 39).

50 Id., ibidem, p. 43.

51 Idem.

52 “Partir, pour monter jusqu'à la cause première, de ma propre existence à moi, sujet pensant, plutôt que d'une autre existence, c'est une simple variation sur le thème de la secunda via de Saint Thomas, où toute existence contingente indifféremment est apte, dès l'instant qu'elle est bien vérifiée, à servir de point de départ. Mais Descartes ne cherche pas la cause première de sont être, il cherche la cause de son être en tant même qu'il pense l'idée de Dieu. Les autres différences qu'il assigne entre sa preuve et la voie thomiste sont illusoires ou secondaires, celle-là est essentielle et fondamentale; la preuve cartésienne est originale, elle procédera tout autrement que les preuves traditionelles" (MARTTAIN, J. Le songe de Descartes, p. 176). 
simples idéia". ${ }^{53} \mathrm{E}$ é provável que tenha tido sucesso nessa empresa, por exemplo, Jesús García López, após ter traçado as linhas fundamentais de uma demonstração válida ("à luz da verdadeira doutrina"54 - tomista), avalia positivamente o segundo argumento cartesiano:

\begin{abstract}
"Estas seriam as linhas fundamentais de uma demonstração de Deus, perfeitamente válida e que coincide em seu sentido geral com a segunda prova cartesiana que analisamos. As insuficiências e falhas da demonstração de Descartes ficariam assim superadas"55 (grifo nosso).
\end{abstract}

Bastante diferente é a posição de Cottingham. Ele chama esta segunda prova com o título "Coda ${ }^{56} \mathrm{O}$ Argumento da Marca Impressa. Segunda Versão". ${ }^{57}$ Sustenta que esta versão "não funciona sem se apoiar nos resultados supostamente conseguidos pela primeira versão". E como a primeira versão, supõe que os leitores compreendam e aceitem o princípio de causalidade. Acrescenta:

\begin{abstract}
“[...] e, em particular, apóia-se na noção, supostamente estabelecida no primeiro argumento de que este principio se pode aplicar ao conteúdo representacional (ou 'realidade objetiva') da idéia de Deus: qualquer que tenha sido a causa que me deu origem, proclama, deverá ser em definitivo suficientemente perfeita para explicar a minha idéia sobre a idéia de Deus." 58
\end{abstract}

Contudo, Cottingham reconhece que alguns comentadores exploram bastante um aspecto específico interessante deste segundo argumento, o da descontinuidade do tempo. Não obstante, considera que como a primeira versão falhou e a segunda também não obterá resultado satisfatório, "será portanto melhor avançar sem mais alarido" 59 (!) ao argumento a priori.

\title{
A terceira prova
}

Após examinar, na quarta das Meditações, que Deus é verídico, que não é enganador e que a fonte do erro reside na vontade ("muito mais ampla e extensa que $o$ entendimento, [...] ela se perde muito facilmente e escolhe $[. ..] \circ$ falso pelo verdadeiro", ${ }^{60}(\mathrm{M}, \mathrm{IV}, 10, \mathrm{p} .51)$, Descartes examinará, na Meditação Quinta, o argumento a priori da existência de Deus. Esta prova não conclui a existência de Deus a partir da existência do eu e da existência de uma idéia no eu, mas a partir da própria essência de Deus.

53 ALQUIÉ, F. A Filosofia de Descartes, p. 86.

54 LÓPEZ, J. G. El conocimiento de Dios en Descartes, p. 111.

55 "Estas serian las lineas fundamentales de una demonstración de Dios, perfectamente válida y que coincide en su sentido general con la segunda prueba cartesiana que hemos analizado. Las insuficiencias y fallos de la demonstración de Descartes quedarían así superados" (Id., ibidem, p. 123).

Coda é um termo utilizado em música. Na fuga real (composição polifônica, em estilo contrapontistico, sobre um tema único), a coda é o prolongamento do sujeito, para facilitar a entrada da resposta.

57 COTTINGHAM, J. A Filosofia de Descartes, p. 83.

58 Id., ibidem, p. 84.

59 COTTINGHAM, J. A Filosofia de Descartes, p. 83.

60 “[...] beaucoup plus ample et plus étendue que l'entendement, [...] elle s'égare fort aisément et choisit [...] le faux pour le vrai" (OL, p. 306; AT IX-1, p. 46). 
Nas Meditações a prova se desenvolve do seguinte modo: o eu encontra em si a idéia de Deus, ou seja, de um ser perfeito, da mesma forma que encontra idéia de qualquer figura ou número; sabe, por outro lado, que pode considerar como verdadeiro tudo o que concebe clara e distintamente nessas idéias; destarte, se encontra na idéia que possui de Deus alguma propriedade que concebe clara e distintamente, saberá que esta propriedade pertence verdadeiramente à essência de Deus, da mesma forma como se sabe, por exemplo, afirma Descartes, que

“[...] da essência de um triângulo retilíneo não pode ser separada a grandeza de seus três ângulos iguais a dois retos ou, da idéia de uma montanha a idéia de um vale; de sorte que näo sinto menos repugnância em conceber um Deus (isto é, um ser soberanamente perfeito) ao qual falte existência (isto é, ao qual falte alguma perfeição), do que em conceber uma montanha que não tenha vale"611 (M, V, 7, p. 57).

Descartes admite uma certa aparência de sofisma nesta prova, pois estamos acostumados a distinguir, em todas as coisas, a essência e a existência. Como conseqüência disso, é-se persuadido, com facilidade, que também em Deus essência e existência podem ser separadas e que é possivel conceber Deus como não existindo atualmente. No entanto, isto não pode ser aplicado a Deus, afirma Descartes: "[...] quando penso nisso com maior atenção, verifico claramente que a existência não pode ser separada de essência de Deus"62 (M, V, 7, p. 57).

$\mathrm{O}$ fato de conceber Deus está restrito ao pensamento. Mesmo que não se possa conceber um Deus sem existência, como uma montanha sem vale, isto não implica que deve existir algum Deus ou alguma montanha no mundo. Pois, afirma Descartes,

“[...] meu pensamento não impõe necessidade alguma às coisas; e como só depende de mim o imaginar um cavalo alado, ainda que não haja nenhum que disponha de asas, assim eu poderia, talvez, atribuir existência a Deus, ainda que não houvesse Deus algum existente" ${ }^{\prime 63}(\mathrm{M}, \mathrm{V}, 8, \mathrm{p} .57)$.

Todavia, "não é assim"64 (M, V, 8, p. 57), esta objeção esconde um sofisma. Por não se poder conceber uma montanha sem vale, não segue que devam existir na realidade, mas somente que, existentes ou não, são inseparáveis. Este raciocínio, entretanto, não pode ser aplicado a Deus, escreve Descartes: “[...] do simples fato de eu não póder conceber Deus sem existência, segue-se que a existência lhe é inseparável, e, portanto, que existe verdadeiramente"65 (M, V, 8, p. 57).

61 “[...] de l'essence d'un triangle rectiligne la grandeur de ses trois angles égaux à deux droits, ou bien de l'idée d'une montagne l'idée d'une vallée; en sorte qu'il n'y a pas moins de répugnance de concevoir un Dieu (c'est-à-dire un être souverainement parfait) auquel manque l'existence (c'est-à-dire auquel manque quelque perfection), que de concevoir une montagne qui n'ait point de vallée" (OL, p. 312; AT IX-1, p. 52).

62 “[...] lorsque j'y pense avec plus d'attention, je trouve manifestement que l'existence ne peut non plus être séparée de l'essence de Dieu" (OL, p. 312; AT IX-1, p. 52).

63 “[...] ma pensée n'impose aucune nécessité aux choses; et comme il ne tient qu'à moi d'imaginer un cheval ailé, encore qu'il n'y en ait aucun qui ait des ailes, ainsi je pourrais peut-être attribuer l'existence à Dieu, encore qu'il n'y eût aucun Dieu qui existât" (OL, p. 313; AT IX-1, p. 53).

64 "Tant s'en faut" (OL, p. 313; AT IX-1, p. 53).

65 “[...] de cela seul que je ne puis concevoir Dieu sans existence, il s'ensuit que l'existence est inséparable de lui, et partant qu'il existe véritablement" (OL, p. 313; AT IX-1, p. 53). 
Descartes, com isso, não quer afirmar que o pensamento engendre as coisas ou se lhe imponha qualquer necessidade. Dá-se justamente o inverso:

"[...] a necessidade da própria coisa, a saber, da existência de Deus, determina meu pensamento a concebê-lo dessa maneira. Pois não está em minhha liberdade conceber um Deus sem existência (isto é, um ser soberanamente perfeito sem uma soberana perfeição)" ${ }^{\prime 66}(\mathrm{M}$, V, 8, p. 57).

Esta liberdade é dada, no entanto, para se imaginar quimeras, ou no exemplo de Descartes, "imaginar um cavalo com asas ou sem asas"67 ( $M, V, 8$, p. 57). A necessidade é característica somente da idéia de Deus.

Concedendo que Deus possui todas as sortes de perfeições, e que a existência é uma delas, não se estaria partindo de uma premissa falsa que invalidaria a conclusão, da mesma maneira como se pensa que é necessário conceber que as figuras de quatro lados se podem inscrever no círculo e, sendo um rombóide uma figura de quatro lados, deveria necessariamente inscrever-se? Ora, isto é falso manifestamente, apesar de ser uma figura de quatro lados um rombóide não pode ser inscrito num círculo. Esta objeção, contudo, não pode ser ąceita. Afirma Descartes:

“[...] pois, ainda que não seja necessário que eu incida jamais em algum pensamento de Deus, todas as vezes, no entanto, que me ocorrer pensar num ser primeiro e soberano, e tirar, por assim dizer, sua idéia do tesouro de meu espirito, é necessário que eu lhe atribua todas as espécies de perfeição, embora eu não chegue a enumerá-las todas e a aplicar minha atenção a cada uma delas em particular"68 (M, V, 9, p. 58).

Esta necessidade é suficiente para concluir, uma vez que se reconheça que a existência é uma perfeição, que este ser primeiro e soberano existe verdadeiramente. Continua Descartes, dando um caráter de certeza matemática a seu argumento:

“[...] do mesmo modo que não é necessánio que jamais eu imagine triângulo algum; mas todas as vezes que quero considerar uma figura retilínea composta somente de três ângulos é absolutamente necessário que eu the atribua todas as coisas que servem para concluir que seus três ângulos não são maiores que dois retos, ainda que talvez não considere então isto em particular"69 (M, V, 9, p. 58).

Descartes finaliza a discussão desta objeção, sustentando que há uma grande diferença entre as falsas suposições (como a de a inscrição de um rombóide num

66 “[...] la nécessité de la chose même, à savoir de l'existence de Dieu, détermine ma pensée à le concevoir de cette façon. Car il n'est pas en ma liberté de concevoir un Dieu sans existence (c'està-dire un être souverainement parfait sans une souveraine perfection)" (OL, p. 313; AT IX-1, p. 53).

67 "[...] imaginer um cheval sans ailes ou avec des ailes" (OL, p. 313; AT IX-1, p. 53).

68 “[...] car encore qu'il ne soit pas nécessaire que je tombe jamais dans aucune pensée de Dieu, néanmoins, toutes les fois qu'il m'arrive de penser à un être premier et souverain, et de tirer, pour ainsi dire, son idée du trésor de mon esprit, il est nécessaire que je lui attribue toutes sortes de perfections, quoique je ne vienne pas à les nombrer toutes, et à appliquer mon attention sur chacune d'elles en particuler" (OL, p. 313-314; AT IX-1, p. 53).

69 “[...] de même qu'il n'est pas nécessaire que j'imagine jamais aucun triangle; mais toutes les fois que je veux considérer une figure rectiligne composée seulement de trois angles, il est absolument nécessaire que je lui attribue toutes les choses qui servent à conclure que ses trois angles ne sont pas plus grands que deux droits, encore que peut-être je ne considère pas alors cela en particuler" (OL, p. 314; AT IX-1, p. 53-54). 
circulo ser necessariamente) e "as verdadeiras idéias que nasceram comigo e, dentre as quais, a primeira e principal que é a de Deus"70 (M, V, 9, p. 58).

A idéia de Deus não é inventada, forjada ou fingida, ou ainda, dependente somente do pensamento, mas "é a imagem de uma natureza verdadeira e imutável"71 ( $\mathrm{M}, \mathrm{V}, 10, \mathrm{p} .58)$. Isto por dois motivos: "Primeiramente, porque eu nada poderia conceber, exceto Deus só, a cuja essência a existência pertence com necessidade"72 ( $\mathrm{M}, \mathrm{V}, 10, \mathrm{p}$. 58). Segundo, porque não é possível conceber mais de um Deus de igual maneira. Tendo-se presente, claramente, que há um Deus agora, segue que tenha existido e que existirá eternamente.

Qualquer prova ou argumento deverá voltar sempre a este ponto: somente as coisas concebidas de forma clara e distinta têm força de persuasão. E manifestando mais uma vez a excelência do conhecimento que independe dos sentidos, afirma Descartes sobre Deus:

"E no que concerne a Deus, certamente, se meu espirito não estivesse prevenido por quaisquer prejuizos e se meu pensamento não se encontrasse distraído pela presença contínua das imagens das coisas sensiveis, não haveria coisa alguma que eu conhecesse melhor nem mais facilmente do que ele. Pois haverá algo por si mais claro e mais manifesto do que pensar que há um Deus, isto é, um ser soberano e perfeito, em cuja idéia, e somente nela, a existência necessária ou eterna está incluida e, por conseguinte, que existe?"73 (M, V, 11, p. 59).

A idéia de Deus, por fim, conquanto é percebida pelo espírito no final de uma ascese "[...] eu tivesse necessitado de grande aplicação de espirito"? (M, V, 12, p. 59), torna-se a mais segura de todas as idéias. Mais, sem ela é impossivel conhecer algo perfeitamente, ela se toma, assim, a garantia de todo conhecimento.

No Discurso tem-se o esboço do argumento a priori:

“[...] voltando a examinar a idéia que tinha de um Ser perfeito, verificava que a existência estava ai inclusa, da mesma forma como na de um triângulo está incluso serem seus três ângulos iguais a dois retos [...]; e por conseguinte, é pelos menos tão certo que Deus, que é esse Ser perfeito, è ou existe, quanto sê-lo-ia qualquer demonstração de geometria"75 (DM, IV, p. 49).

70 "les véritables idées qui sont nées avec moi, dont la première et principal est celle de Dieu" (OL, p. 314; AT IX-1, p. 54).

71 “[...] c'est l'image d'une vraie et immuable nature" (OL, p. 314; AT IX-1, p. 54).

72 "Premièrement, à cause que je ne saurais concevoir autre chose que Dieu seul, à l'essence de laquelle l'existence appartienne avec nécessité" (OL, p. 314; AT IX-1, p. 54).

73 "Et pour ce qui est de Dieu, certes, si mon esprit n'était prévenu d'aucuns préjugés, et que ma pensée ne se trouvât point divertie par la présence continuelle des images des choses sensibles, il n'y aurait aucune chose que je connusse plutôt ni plus facilement que lui. Car y a-t-il rien de soi plus clair et plus manifeste, que de penser qu'il y a un Dieu, c'est-à-dire un être souverain et parfait, en l'idée duquel seul l'existence nécessaire ou étemelle est comprise, et par conséquent qui existe?" (OL, p. 315; AT IX-1, p. 54-55).

74 “[...] j'aie eu besoin d'une grande application d'esprit" (OL, p. 315; AT IX-1, p. 55).

75 “[...] revenant à examiner l'idée que j'avais d'un Être parfait, je trouvais que l'existence y était comprise en même façon qu'il est compris en celle d'un triangle que ses trois angles sont égaux à deux droits [...]; et que, par conséquent, il est pour le moins aussi certain que Dieu, qui est cet Être parfait, est ou existe qu'aucune démonstration de géométrie le saurait être" (OL, p. 150; AT VI, p. 36). 
Nos Princípios, no artigo 14 do primeiro livro, Descartes apresenta resumidamente a terceira prova: "Pode-se demonstrar que há um Deus, apenas porque a necessidade de ser ou de existir está compreendida em a noção que temos dele"76 (PF, I, 14, p. 64).

Outra versão do argumento a priori fora apresentada, muitos séculos antes de Descartes, por Santo Anselmo de Aosta ${ }^{77}$ (1033-1109), arcebispo de Cantuária, com o seu "Deus quo maius cogitari non possit". ${ }^{78}$ Questionado por Caterus (autor das Primeiras Objeções) se o seu argumento não seria uma reedição do argumento anselmiano, Descartes responde que não conhecia a obra de Santo Anselmo e que iria à biblioteca consultá-la. ${ }^{79}$ Ao Pe. Mersenne escreve, em dezembro de 1640, que verá Santo Anselmo na primeira oportunidade. ${ }^{80}$ Caterus, referindo-se a Santo Tomás, critica o argumento cartesiano:

"Ainda concedendo que só o ser sumamente perfeito inclui em seu conceito a existência, disso não se segue que precisamente essa existência seja algo real na natureza das coisas, senão unicamente que o conceito de existência está ligado inseparavelmente ao conceito de ser supremo." 81

Hans Küng chama a atenção para o fato de que o argumento ontológico somente mantém sua força de convencimento enquanto prevalece a perspectiva platônico-agostiniana de um realismo das idéias, em que as idéias têm realidade própria e independente, esta é a perspectiva de Descartes:

“Também para Descartes a idéia não era em absoluto mero pensamento, palavra vazia, 'simples' conceito, senão uma realidade primigênia. Em tal caso, naturalmente, se poderia concluir da realidade da idéia de Deus a realidade de sua existência." 82

Fraile aponta como Descartes joga com as categorias de idéia e realidade:

"Em toda sua argumentação vemos Descartes jogando indistintamente com a idéia e com a realidade, exagerando o alcance da 'idéia objetiva'. Supõe que temos em nossa mente a

76 “Ou'on peut démontrer qu'il y a un Dieu de cela seul que la nécessité d'être ou d'exister est comprise en la notion que nous avons de lui" (OL, p. 577; AT IX-2, p. 31).

77 Ver a este respeito: STREFLING, Sérgio Ricardo. O argumento ontológico de Santo Anselmo. Porto Alegre: EDIPUCRS, 1993; ZILLES, Urbano. O Problema do Conhecimento de Deus. Porto Alegre: EDIPUCRS/Acadêmica, 1989. Este apresenta o argumento de Santo Anselmo no segundo capitulo, Caminhos Racionais, juntamente com as cinco vias de Santo Tomás; apresenta, ainda, os caminhos não-racionais, os não exclusivamente racionais e a questão fé e ciência hoje. Aqquele é completamente dedicado ao estudo do argumento anselmiano, apresentando o contexto da época, o argumento e sua discussâo.

ZILLES, U. Filosofia da Religião, p. 29.

79 FRAILE, G. Historia de la Filosofía, v. III, p. 527.

80 "Je verrai St. Anselme à la première occasion" (OL, p. 1102).

81 "Encore que l'on demeure d'accord que l'être souverainement parfait par son propre nom emporte l'existence, néanmoins il ne s'ensuit pas que cette même existence soit dans la nature actuellement quelque chose, mais seulement qu'avec le concept, ou la notion de l'être souverainement parfait" (OL, p. 342; AT IX-1, p. 79).

82 "También para Descartes la idea no era en absoluto mero pensamiento, palabra vacia, 'simple' concepto, sino una realidad primigenia. En tal caso, naturalmente, si se podia concluir de la realidad de la idea de Dios la realidad de su existencia" (KÜNG, H. ¿Existe Dios? 4. ed. Madrid: Ediciones Cristandad, 1979 p. 66). 
'idéia objetiva' de um ser perfeito e infinito, ao qual identifica um Deus, e que nesta idéia vemos contida sua existência necessária." ${ }^{83}$

O argumento de Santo Anselmo já havia sido criticado por Santo Tomás. Foi amplamente criticado por Kant, que o denominará, como já foi referido, argumento ontológico. ${ }^{84}$ É também denominado argumento a simultaneo, porque na idéia de Deus está incluída sua existência. ${ }^{85}$ Para Kant, neste argumento, procede-se a uma abstração de toda experiência e a existência de Deus é inferida a priori dos conceitos; faz-se uma passagem, indevida, do nível lógico ao ontológico.

Tanto o argumento anselmiano quanto o terceiro de Descartes, partem da idéia para a existência. Porém, possuem matizes distintos. Fraile afirma que Santo Anselmo apóia seu raciocínio na grandeza de Deus, enquanto Descartes se fixa em sua perfeição infinita. ${ }^{86}$ Descartes dá a seu argumento uma formulação matemática. As provas diferem, também, profundamente pelo clima que envolve cada uma delas. Fraile afirma que Descartes chega a dar razão a Santo Tomás na critica que este faz da prova anselmiana e protesta que a prova de Anselmo não coincide com a sua. ${ }^{87}$

Segundo Maritain, "a prova ontológica é como um novo ponto de partida absoluto da filosofia cartesiana" ${ }^{88} \mathrm{Na}$ mesma perspectiva segue Hamelin, sustentando que o cartesianismo subsistiria, quase integralmente, somente com a prova que deriva da idéia de perfeição. Afirma:

“A realidade histórica justifica este ponto de vista, porque a prova ontológica parece ter ocorrido a Descartes no curso de suas meditações, de forma repentina e inesperada e a não duvidá-lo, a recebeu satisfeito, porque significaria um novo recurso para seu sistema." 89

Para Hamelin, uma vez colocada a existência de Deus pela prova ontológica, Descartes dá seguimento ao seu sistema, ou seja, passa a tratar do problema da existência das coisas materiais.

Alguns autores sugerem que Descartes não estava totalmente satisfeito com o argumento ontológico, ou pelo menos, não o considerava tão rigoroso como o primeiro argumento. Nesta linha segue Guéroult, afirmando que a prova ontológica tem sua realidade, como as matemáticas, condicionada pela prova baseada nos efeitos (primeira prova), deriva dela e não pode subsistir sem ela. "Em conseqüência, a prova pelos efeitos deve ser considerada como a prova principal e mesmo

83 "En toda esta argumentación vemos a Descartes jugando indistintamente con la idea y con la realidad, exagerando el alcance de la 'idea objetiva'. Da por supuesto que tenemos en nuestra mente la 'idea objetiva' de un ser perfecto e infinito, al cual identifica con Dios y que en esa idea vemos contenida su existencia necesaria" (FRAILE, G. Historia de la Filosofia, v. II, p. 527). KANT, Immanuel. Critica da razăo pura. Lisboa: Fundaçăo Calouste Gulbenkian,1985, p. 500 ( L. I, $2^{\mathrm{a}}$ p., $2^{\mathrm{a}}$ d, L 2, cap. $3,4^{\mathrm{a}}$ secção). STREFLING, S. R. O argumento ontológico de Santo Anselmo, p. 9. Idem.

88 "La preuve ontologique est comme un nouveau départ absolu de la philosophie cartésienne" (MARITAIN, Jacques. Le songe de Descartes. Paris: Buchet/Castel. ca. 1931, p. 185).

89 "La realidad histórica justifica este punto de vista porque la prueba ontológica parece habérsele ocurrido a Descartes en el curso de sus meditaciones en forma repentina e inesperada y a no dudarlo la recibió complacido porque significaba un nuevo recurso para su sistema" (HAMELIN, Octave. El sistema de Descartes. Buenos Aires: Editorial Losada, 1949, p. 211). 
única da existência de Deus". ${ }^{90}$ Guéroult afirma, ainda, que a subordinação expressa da prova ontológica à prova pelos efeitos traz algumas importantes conseqüências:

"Ela torna caducas muitas objeções clássicas. Ela arruina primeiramente, [...] a objeção sobre a qual Kant insistirá, e que consiste em negar-lhe todo valor objetivo. Ela refuta de inicio a critica de Kant e de Vico, que denunciam sua orgulhosa pretensāo de encerrar a natureza de Deus nas necessidades de nosso entendimento." 91

Vale lembrar que, nas Meditações, Descartes insiste que para compreender seu argumento é mister abandonar os preconceitos e hábitos do mundo, atender ao caráter inato da idéia de Deus, elevar-se espiritualmente à idéia do infinito. Sem isso, a prova aparecerá sempre como sofisma. Afirma Alquié:

"O objetivo das Meditaçōes é desprender o espirito dos sentidos, abducere mentem a sensibus. A via que elas nos propõem não é somente a de um encadeamento de razões, mas de um itinerário vivido." 92

\section{Quadro das três provas e avaliação}

Jesús García López apresenta, a partir do que afirmou sobre a sistemática das provas cartesianas da existência de Deus, o seguinte quadro: ${ }^{93}$

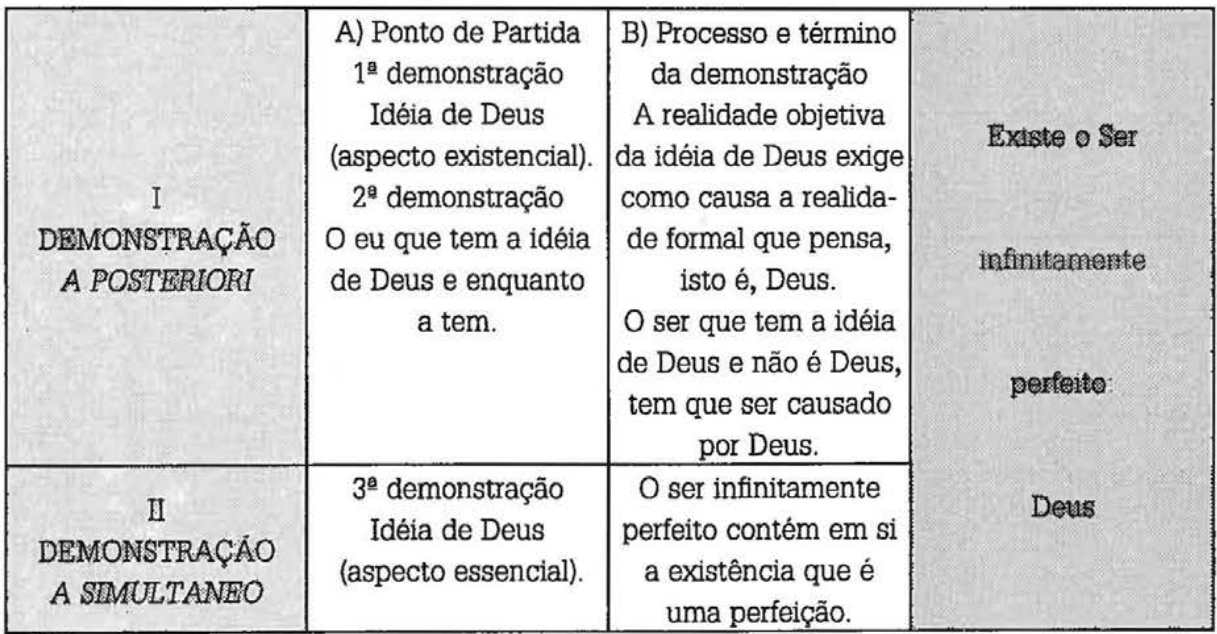

90 "En conséquence la preuve par les effets doit être considérée comme la preuve principale et même unique de l'existence de Dieu" (GUÉROULT, Martial. Descartes selon l'ordre des raisons. Paris: Aubier/Montaigne, 1953. v. I, p. 339).

91 "Elle rend caduques maintes objections classiques. Elle ruine d'abord, [...] celle sur laquelle Kant insistera, et qui consiste à lui dénier toute valeur objective. Elle réfute d'avance la critique de Kant et de Vico, qui dénoncent son orgueilleuse prétention d'enfermer la nature de Dieu dans les nécessités de notre entendement" (Id., ibidem, p. 360).

93 LÓPEZ, J. G. El conocimiento de Dios en Descartes, p. 58. 
Após a apresentação das provas da existência de Deus em Descartes e das considerações dos autores, surge a pergunta sobre o valor que tais provas possuem hodiernamente. U. Zilles, quando avalia o valor do argumento ontológico de Santo Anselmo e, por extensão, das outras provas racionais da existência de Deus - e aqui pode-se incluir as cartesianas, propõe alguns questionamentos:

"Pode uma prova racional provar a existência de Deus? Se as provas da existência de Deus fossem realmente provas, por que descrentes e até crentes as rejeitam como provas? [...] 0 Deus demonstrado ainda pode ser realmente Deus ou seria tratado à maneira de um objeto fisico ou matemático?"${ }^{\prime 4}$

As provas, segundo $\mathrm{H}$. Küng, cujos resultados, ao parecerem tão racionais, despertam hoje um mínimo interesse existencial. ${ }^{95}$ As críticas dirigidas às provas racionais da existência de Deus, contudo, não negam necessariamente o conteúdo nelas expressado. Zilles afirma que "duvidar de seu caráter contundente de demonstração de modo algum invalida seu conteúdo". 96 Apesar de toda a limitação da abordagem, exclusivamente racional da questão de Deus, que desperte hoje pouquíssimo interesse existencial, as provas contêm um elemento precioso: a tematização do infinito, do imponderável e do inefável, "o reconhecimento do elemento incondicional (Tillich) na estrutura da razão e da realidade". ${ }^{97}$ A questão de Deus excede imensamente o âmbito da simples razão.

\section{Abreviaturas}

AT - DESCARTES, René. Oeuvres de Descartes; publiées par Charles Adam e Paul Tannery. Paris: Vrin/CNRC, 1971-1974. $12 \mathrm{v}$.

OL - $\quad$ Oeuvres et Lettres; textes présentés par André Bridoux. Paris: Gallimard, 1952 (Bibliothèque de La Pléiade).

DM; M - D. Discurso do Método; Meditações Metafisicas. 4. ed. São Paulo: Nova Cultural (Coleção Os Pensadores), 1987-1988. 2 v.

$\mathrm{PF}$ - $\quad$ Principios da Filosofia. 4. ed. Lisboa: Guimarães Editores, 1989.

94 ZILLES, U. O problema do conhecimento de Deus, p. 23.

95 Cf. KÜNG, H. ¿Existe Dios? p. 52.

96 ZILLES, U. O problema do conhecimento de Deus, p. 23.

97 Idem. 